\title{
Sport specific rehabilitation: the Barcelona Football Club vision
}

\author{
Ricard Pruna ${ }^{1}$ \\ Xavier Valle ${ }^{1}$ \\ Zafar lqbal ${ }^{2}$ \\ Nicola Maffulli3,4,5 \\ Nikolaos Malliaropoulos 4,6
}

1 FC Barcelona. FIFA Medical Center of Excellence, Sant Joan Despí, Barcelona, Spain

2 Head of Sports Medicine, Crystal Palace FC, Consultant in Sports and Exercise Medicine, Medical Officer, Kent Cricket Club, England

3 Department of Trauma and Orthopaedics, University of Salerno School of Medicine, Salerno, Italy

4 The Centre for Sports and Exercise Medicine, The William Harvey Research Institute, The Bart's and The London School of Medicine and Dentistry, Queen Mary, University of London, London, England

5 The Institute of Science and Technology in Medicine, Keele University School of Medicine, Stoke on Trent, England

6 Thessaloniki MSK Sports Medicine Clinic, ThessaIoniki, Greece

\section{Corresponding author:}

Nicola Maffulli

Department of Musculoskeletal Disorders

School of Medicine and Surgery,

University of Salerno,

Mary University of London

Barts and the London School of Medicine and Dentistry

Centre for Sports and Exercise Medicine

Mile End Hospital 275 Bancroft Road

E1 4DG, London, England, UK

Tel.: +447989358279

E-mail: n.maffulli@qmul.ac.uk

\section{Summary}

Following an injury, the appropriate recovery methodology is vital to return athletes quickly and safely to their sport. Traditionally, rehabilitation stages are planned according to pre-established milestone. In this way, if a re-injury occurs, it is possible to exactly identify at what stage something may have not been managed appropriately. During rehabilitation, adequate and appropriate cognitive and neuromuscular skills should be main- tained, allowing the athlete to protect the injured part during the biological time needed for it to heal. An athlete should be exposed to their sport specific skills as much as possible, adapting intensity, velocity and power. This would allow adaption and healing of the injured tissue, restoring as quickly as possible the specific movements or loads expected from the injured muscle or joint.

KEY WORDS: return to play, injuries, rehabilitation.

\section{Introduction}

Charles Darwin stated "It is not the strongest of the species that survives, nor the most intelligent that survives. It is the one that is most adaptable to change". Success is everything in professional sport. Injuries are inevitable when pushing the body to the limits in contact sports: this should be understood as an adaptive process. The appropriate recovery methodology is vital in trying to return the athlete as quickly and as safely to their sport. Traditionally, rehabilitation stages are planned according to clinical signs, test or milestone to be passed before progressing. This approach allows both the athlete and the treating clinician to understand the progressions; if a re-injury occurs, it is possible to exactly identify at what stage something may have not been managed appropriately.

Obviously, the ideal scenario would be an athlete competing without symptoms, imbalances and weaknesses. Nevertheless, we are at times faced with athletes training and competing but having to cope with discomfort or weaknesses from the pressures of returning to competition.

Frequently, physical screening of competing athletes will show biomechanical abnormalities; however, these athletes are performing, and it is therefore difficult to stop them playing while waiting to correct the perceived deficiencies. The aim is then to help to adapt, allowing them to compete and perform at the highest level through the injury. The disadvantage with this latter approach is that players may take longer to return to sports-specific activity if that is only started when there is 'normal' restoration of strength or function based on pre-injury screening or standard values. Ideally, the focus should be more on the biological time needed for the injury to recover, while trying to maintain the skills of the athlete during the rehabilitation process. 
"Delay in rehabilitation can result in prolonged pain and a delayed return to sports, a finding that emphasizes the importance of regular and controlled mechanical loading early after trauma to large muscles"1. In this context, neuroplasticity refers to the ability of the central nervous systems to compensate for injury and disease, and to adjust it activities in response to new situations or to changes in our environment $^{2}$. Neuroplasticity exerts an important role in performance and adaptability of the musculoskeletal system. Therefore, a key point during the rehabilitation and decision making process should be to maintain adequate and appropriate cognitive and neuromuscular skills. Neuroplasticity allows to correct, modify, and adapt neuromuscular patterns, allowing the athlete to protect the injured part during the biological time needed for it to heal. For example, during the whole rehabilitation process, a footballer should be exposed to "football specific skills" as much as possible, adapting intensity, velocity and power. This would allow adaption and healing of the injured tissue, restoring as quickly as possible the specific movements or loads expected from the injured muscle or joint.

Currently, at Barcelona FC, the players do not go through the traditional model of rehabilitation. Many of the players wish to minimise the loss of their technical skills during rehabilitation given its key role in FC Barcelona model of game. We will be accused of bias; we are talking about elite athletes genetically gifted and perhaps even more protected in front injuries $^{3-5}$. FC Barcelona players are technically excellent, and may well have a better understanding of their own bodies, or be able to cope better hence why they have been so successful.

This form of rehabilitation may be deemed more subjective and reliant largely on the individual rehabilitators experience. In this context, it may not be as easy to show objective progressions or measures, although all processes are monitored using GPS data previously recorded from all the players during training and matches 6 . The rehabilitation process aims to reach the training or match GPS data performance metrics of the player, but by undertaking football specific drills. So, as part of the rehabilitation process, we should be targeting the injured tissue to adapt as quickly as possible to the activities that will be expected for them to perform.

In conclusion, return to play in professional football should be understood as the decision making process that allows the players to return at their maximum competition level, whether or not the injury is completely healed, and avoid re-injuries. But what is the best way to achieve this?

The Barcelona FC believes that retaining football skills is the priority, and that players will be able to return to training and minimising loss of football related skills if the focus is on football based functional rehabilitation as opposed to gym + GPS based rehabilita- tion. The difficulty is trying to prove this, as it may only work with certain types of players. Hopefully, this model will be applicable to other sports where the technical aspects of the sport themselves make relying on technical skills a major determinant of performance and success.

\section{Author contributions}

All Authors contributed to writing, editing the manuscript critically revising the paper and agree to be accountable for all aspects of the work.

\section{Transparency statement and data sharing statement}

The Authors affirm that this manuscript is an honest, accurate, and transparent account of the study being reported; that no important aspects of the paper have been omitted; and that any discrepancies from the paper as planned (and, if relevant, registered) have been explained.

\section{Ethics}

The Authors declare that this research was conducted following basic ethical aspects and international standards as required by the journal and recently update in ${ }^{7}$.

\section{References}

1. Bayer ML, Magnusson SP, Kjaer M. Early versus Delayed Rehabilitation after Acute Muscle Injury. New England Journal of Medicine. 2017;377(13):1300-1301.

2. Kami A, Meyer G, Jezzard P, Adams MM, Turner R, Ungerleider LG. Functional MRI evidence for adult motor cortex plasticity during motor skill learning. Nature. 1995;377(6545):155.

3. Artells R, Pruna R, Dellal A, Maffulli N. Elastin: a possible genetic biomarker for more severe ligament injuries in elite soccer. A pilot study. MLTJ 2016 Sep 17;6(2):188-192.

4. Pruna R, Artells R, Lundblad M, Maffulli N. Genetic biomarkers in non-contact muscle injuries in elite soccer players. Knee Surg Sports Traumatol Arthrosc. 2017 Oct;25(10):3311-3318.

5. Pruna R, Artells R, Ribas J, Montoro B, Cos F, Muñoz C, Rodas G, Maffulli N. Single nucleotide polymorphisms associated with non-contact soft tissue injuries in elite professional soccer players: influence on degree of injury and recovery time. BMC Musculoskelet Disord. 2013 Jul 26;14:221.

6. Ehrmann FE, Duncan CS, Sindhusake D, Franzsen WN, Greene DA. GPS and injury prevention in professional soccer. The Journal of Strength \& Conditioning Research. 2016;30 (2):360-367.

7. Padulo J, Oliva F, Frizziero A, Maffulli N. Muscles, Ligaments and Tendons Journal - Basic principles and recommendations in clinical and field science research: 2016 update. MLTJ. 2016;6(1):1-5. 